Jurnal Riset Agama

Volume 1, Nomor 2 (Agustus 2021): 365-374

DOI: $10.15575 /$ jra.v1i2.14597

https://journal.uinsgd.ac.id/index.php/jra

\title{
Hadis tentang Berhubungan Badan di Luar Pernikahan
}

\author{
Salis Abdalah Hatami \\ Jurusan Ilmu Hadis, Fakultas Ushuluddin \\ UIN Sunan Gunung Djati Bandung \\ abdalahhatami@gmail.com
}

\begin{abstract}
This study aims to discuss how the explanation of having sex outside of marriage in the perspective of hadith. This research uses qualitative type method with content analysis through literature study. The results and discussion in this study include a general view of adultery, takhrij sanad in the hadith regarding adultery, and how to explain the prohibition of adultery. The conclusion of this study shows that adultery is a behavior that is prohibited both religiously and legally in Indonesia, and the hadith that explains the prohibition of adultery is a saheeh hadith. This study warns of the dangers and other negative impacts of adultery.
\end{abstract}

Keywords: Hadith; Marriage; Sex.

\begin{abstract}
Abstrak
Penelitian ini bertujuan membahas bagaimana penjelasan berhubungan badan di luar pernikahan dalam perspektif hadis. Penelitian ini menggunakan metode jenis kualitatif dengan analisis isi melalui studi pustaka. Hasil dan pembahasan pada penelitian ini mencakup pandangan umum tentang zina, takhrij sanad pada hadis mengenai zina, dan bagaimana keterangan perihal larangan zina. Kesimpulan penelitian ini menunjukkan bahwa zina adalah perilaku yang dilarang baik secara agama maupun hukum di Indonesia, dan hadis yang menjelaskan perihal larangan zina adalah hadis yang shahih. Penelitian ini mengingatkan akan bahaya dan dampak negatif lainnya akibat perilaku zina.
\end{abstract}

Kata kunci: Berhubungan; Badan; Hadis; Pernikahan. 
Jurnal Riset Agama, Volume 1, Nomor 2 (Agustus 2021): 365-374

Salis Abdalah Hatami/Hadis tentang Berhubungan Badan di Luar Pernikahan

\section{Pendahuluan}

Berhubungan badan di luar pernikahan adalah hal yang dianggap tabu. Berhubungan seksual yang dilakukan di luar pernikahan akan dipandang tercela dan bahkan sangat dilarang dalam agama Islam. Dalam hukum Islam perzinahan dianggap sebagai suatu perbuatan yang sangat terkutuk dan dianggap sebagai jarimah. Pendapat ini disepakati oleh ulama, kecuali perbedaan hukumannya. Namun, menurut sebagian ulama tanpa memandang pelakunya, baik dilakukan oleh orang yang belum menikah atau orang yang telah menikah, selama persetubuhan tersebut berada di luar kerangka pernikahan, hal itu disebut sebagai zina dan dianggap sebagai perbuatan melawan hukum. Oleh karena itu, walaupun zina dilakukan secara sukarela atau suka sama suka, tetap tidak mengurangi nilai kepidanaannya(Hadi Wihyono,Achmad Manaf, 2020).

Sejumlah pakar telah melakukan penelitian tentang hal tersebut sebagaimana dalam tinjauan pustaka ini. Antara lain Hilman (2014), "Delik Perzinaan Ditinjau dari Perspektip Hukum Islam," Fakultas Hukum Universitas Ibn Khaldun Bogor. Penelitian ini membahas tentang hubungan seksual yang tidak sah yang dilakukan oleh laki-laki dan perempuan di luar ikatan perkawinan. Larangan zina baik yang terdapat dalam Al-qur'an maupun hadis, selain dalam rangka amar makruf nahi munkar juga dimaksudkan untuk memelihara keturunan dan kehormatan(Hilman, 2014). Alvi, M.Hasballah, Marlina. (2016), "Perzinahan dalam Perspektif Islam Sebagai Alternatif Pembaharuan Hukum Pidana Tentang Perzinahan," USU Law Jurnal. Penelitian ini membahasa tentang perzinahan dalam figh jinayah. Memberikan efek sembuh bagi para pelaku dan menghukum dengan hukum Islam (Alvi, M.Hasballah, Marlina, 2016). Amalia (2018), "Prostitusi dan Perzinahan dalam Perspektif Hukum Islam," Fakultas Hukum Universitas Suryakencana. Penelitian ini mengarah pada hukum perzinahan dalam konsep hukum Islam yang jauh berbeda dengan hukum konvensional. Upaya yang dilakukan dalam mengatasi perzinahan dan membentuk hukum perzinahan sesuai dengan petunjuk Al-qur'an dan hadis (Amalia, 2018).

Berbagai penelitian terdahulu berharga bagi penyusunan kerangka berpikir penelitian ini. Berhubungan badan di luar pernikahan adalah hubugan seksual yang dilkukan oleh laki-laki dan perempuan di luar ikatan perkawinan(Hilman, 2014). Berhubugan badan di luar pernikahan adalah hubungan kelamin antara seorang lelaki dengan seorang perempuan yang satu sama lain tidak terikat dengan hubungan perkawinan, sehingga siapapun mereka jika melakukan persetubuhan dengan orang yang bukan seuami atau istrinya maka dihukumi zina (Huda, 2015). Dalam pemahaman mayarakat Indonesia berhubungan badan di luar pernikahan termasuk jenis pelanggaran yang termasuk 
kedalam kelompok kejahahatan kesusilaan (Bahiej, 2003). Sabda Nabi Saw tentamg berhubungam badan di luar permikaham (zina) tersebar dalam kitab-kitab hadis yang diriwayatkan oleh Muslim, Bukkhori, Abu Daud, at-Turmudzi, dan an-Nasa'i (Kisworo, 2016). Hadis tentang berhubungan badan di luar pernikahan dari segi dan matan berkualitas shahih (Risma 2013). Para ulamaa sepakaat menyatakan keharaman khalwat yang tidak disertai mahrom sebagai tindakan preventif agar tidak terjerumus pada perbuatan zina (Fatih, 2019). Hadis yang melarang beerhubungan badan di luar pernikahan secara tegas terdapat di dalam Bukhari dan Muslim (Fakhtu, 2019). Syarah hadis tentang haramnya berhubungan badan di luar pernikahan secara jelas dan tegas (Mayra, 2013). Zina adalah dosa yang sangat besar dan sangat keji serta seburukburukya jalan yang ditempuh oleh seseorang(Hadziq, 2019).

Berdasarkan paparan di atas, formula penelitian disusun, yaitu rumusan masalah penelitian, pertanyaan utama penelitian, dan tujuan penelitian (Darmalaksana, 2020). Rumusan masalah penelitian ini adalah terdapat hadis mengenai berhubungan badan di luar pernikahan. Pertanyaan utama penelitian ini ialah bagaimana hadis-hadis tentang berhubungan badan di luar pernikahan. Sedangkan pertanyaan penelitian secara terperinci yakni bagaimana pandangan umum tentang berhubungan badan di luar pernikahan, bagaimana hadis-hadis tentang berhubungan badan di luar pernikahan, dan bagaimana hadis larangan berhubungan badan di luar pernikahan. Tujuan penelitian ini yaitu membahas hadis mengenai berhubungan badan di luar pernikahan. Penelitian ini diharapkan bermanfaat bagi pengayaan khazanah pengetahuan Islam.

\section{Metode Penelitian}

Penelitian ini merupakan jenis kualitatif melalui studi pustaka dengan analisis isi (Gunawan, 2013).

\section{Hasil dan Pembahasan}

Hasil dan pembahasan penelitian di bawah ini.

\section{Pandangan Umum tentang Zina (Berhubungan Badan di Luar Pernikahan)}

Di jaman serba modern seperti ini, kita kerap sekali diperlihatkan dengan problematika yang mencemari agama dengan pergaulan yang tanpa dibatasi dengan aturan yang mengikat bagi penganut agama. Hal tersebut menjadi sebuah keperihatinan bagi kita selaku umat yang Islam dengan kebiasaan orang yang sama sekali tidak memperdulikan aturan yang dalam hal ini mereka anggap sebagai batasan atau penghalang dalam melakukan apa yang mereka ingin perbuat, dengan kata lain mengikuti apa kata nafsunya. Saat ini bukan hal yang jarang kita temui 
lagi melihat sepasang remaja bergandengan tangan, bermesra-mesraan, bahkan ada juga yang sampai melakukan ciuman di tempat umum. Pedahal perlu diketahui perilaku tersebut merupakan perilaku yang sangat tidak dibenarkan oleh agama dan mendekatkan pada zina. Zina merupakan perilaku yang sangat tabu di Indonesia, zina sendiri memiliki dua pengertian yang berbeda, yaitu pengertian zina yang bersifat khusus dan pengertian yang bersifat umum. Pengertian zina yang bersifat khusus adalah yang semat-mata mengandung konsekuensi hukum hudud. Sedangkan pengertian zina secara umum meliputi yang berkonsekuensi dihukum hudud dan yang tidak, yaitu hubungan sexsual antara laki-laki dan perempuan diluar ikatan perkawinan (Hadi Wihyono,Achmad Manaf, 2020).

Zina merupakan perbuatan hubungan intim yag dilakuakan oleh sepasang manusia yang sebelumnya tidak terikat dalam hubungan perkawinan. Zina tergolongkan dalam salah satu perilaku yang dilarang untuk diperbuat oleh manusia dengan apapun alasannya. Seluruh aspek dalam kehidupan baik aspek agama, budaya maupun sosial tidak ada yang membenarkann akan perilaku berhubungan badan di luar pernikahan karena merupakan perilaku yang tidak pantas dilakukan oleh manusia. Kehidupan yang terjadi saaat ini telah mengatur perihal dengan perilaku zina. Aturan yang diberlakukan telah diatur oleh segala sudut dalam kehidupan. Adapun sisi yang menonjol dalam memberikan dampak pencegahan dan hukuman perihal perilaku zina adalah dari sisi agama, adat dan hukum negara. Seluruh sisi tersebut mempunyai kesamaan yang menyatakan zina adalah perilaku yang bertolak belakang akan kodrat manusia dan hal yang dilarang untuk dilakukan oleh setiap manusia. Hal tersebut merefleksikan bahwa tidak ada pembenaran dalam perbuatan zina, oleh karena itu menjauhkan perbuatan zina dalam kehidupan adalah hal yang selayaknya manusia lakukan (Hadziq, 2019).

Zina merupakan hal yang dilarang dan dikecam baik oleh agama maupun hukum di Indonesia, walaupun makna zina sendiri memiliki perbedaan dalam pengertian agama dan hukum yang ditegakan di Indonesia, terlepas dari itu tetap saja pengertian keduanya memiliki subtansi yang sama mengenai zina. Ada kalanya zina dilakukan secara sembunyi-sembunyi dan belum diketahui oleh masyarakat. Keadaan yang terjadi demikian, zina yang diperbuat masih dalam zona dosa pribadi. Berbeda keadaannnya apabila telah diketahui oleh masyarakat, hal tersebut akan menjadi dampak negatif dan menggangu ketentraman kehidupan sosial sehingga menjadi dosa sosial. Oleh sebab itu taubat saja tidak cukup, melainkan harus juga dengan memberi sanksi terhadap pelakunya (Kisworo, 2016).

Dalam hukum adat istiadat zina sering disebut dengan dengan kata sumbang. Zina merupakan suatu perilaku yang dapat mencemai atau 
merusak kesusilaan masyarakat. Zina menurut hukum adat merupakan tindak pidana yang dapat mengganggu neraca kesimbangan masyarakat, mencoreng kehormatan kerabat, merusak kesucian masyarakat dan merusak tatanan kehidupan. Hal tersebut sependapat dengan dengan pernyataan Iman Sudiyat yang mengatakan bahwa zina merupakan delik yang terutama melanggar kehormatan kerabat dan melanggar kepentingan hukum seseorang selaku suami. Kemudian menurut $\mathrm{R}$. Soepomo, bahwa zina adalah perbuatan melangar kehormatan golongan family serta melanggar kepentingan kepentingan hukum sebagai seorang suami (Ishaq, 2018).

Pengaturan perihal zina pada sisi agama merujuk pada aturan yang telah ditetapkan Tuhan pada kitab suci agama masing-masing. Misalnya agama Islam, sebagai agama yang dianut oleh mayoritas masyarakat Indonesia mempunyai tindakan akan pelaku zina yang telah disebutkan dalam Al-Qur'an dan Hadis. Dalam agama Islam zina telah ditetapkan perihal larangan maupun hukumannya. Pada agama Islam sendiri hal ini disebut hukum syari'at yang mengikat bagi seluruh umat beragama Islam. Pelaku zina dapat dibuktikan telah berbuat zina apabila adanya pengakuan maupun dengan persaksian. Dalam hal pengakuan, menurut imam Syafi'i dan imam Malik, hukum bias dijatuhkan apabila orang yang mengakuinya dewasa dan berakal. Abu Hanifah, Ahmad, dan Syiah Imamiah berpendapat bahwa hukuman tidak dijatuhkan, kecuali pengakuan pelaku diulang ulang secara empat kali (Hadziq, 2019).

\section{Hadis-hadis tentang Zina (Berhubungan Badan di Luar Pernikahan)}

Terdapat hadis Nabi SAW berkenaan dengan zina dalam kitab shahih Bukhori juz.1 hal. 27 No.78.

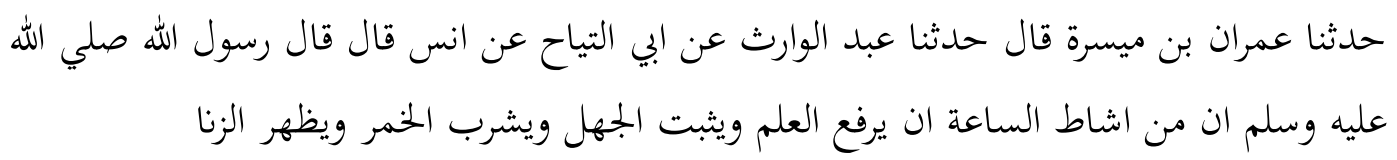

Telah menceritakan kepada kami 'Imran bin Maisarah berkata, telah menceritakan kepada kami Abdul Warits dari Abu At-Tayyah dari Anas bin Malik berkata, telah bersabda Rasul shallallahu 'alaihi wasallam dalam sabdanya berisi bahwasanya tnda-tanda kiamat adalah diambilnya ilmu, kebodohan dimana-mana, khamer diminum, dan perzinahan secara terang-terangan.

Mula-mula dilakukan pencarian pada aplikasi hadis dengan kata kunci “zina" hingga ditemukan hadis pada kitab Shahih Bukhori No.78. 
Tabel 1 Daftar Rawi Sanad

\begin{tabular}{|c|c|c|c|c|c|c|c|}
\hline No. & $\begin{array}{l}\text { Rawi } \\
\text { Sanad }\end{array}$ & Lahir & Wafat & Negeri & Kuniyah & $\begin{array}{l}\text { Komentar } \\
\text { Ulama }\end{array}$ & Thabaqoh \\
\hline & & L & W & & & + & \\
\hline 1 & $\begin{array}{l}\text { Anas bin } \\
\text { Malik }\end{array}$ & $\begin{array}{l}\text { Tidak } \\
\text { Diketahui }\end{array}$ & $90 \mathrm{H}$ & $\begin{array}{l}\text { Madinah, } \\
\text { Basroh }\end{array}$ & $\begin{array}{l}\text { Abu } \\
\text { Hamzah }\end{array}$ & $\begin{array}{l}\text { Shahabi } \\
\text { Masyhur }\end{array}$ & 1 (Sahabat) \\
\hline 2 & $\begin{array}{l}\text { Abi At- } \\
\text { Tayyah }\end{array}$ & $\begin{array}{l}\text { Tidak } \\
\text { Diketahui }\end{array}$ & $128 \mathrm{H}$ & Basroh & $\begin{array}{l}\text { Abu AT- } \\
\text { Tayyahi }\end{array}$ & $\begin{array}{l}\text { Tsiqoh } \\
\text { Tsubut }\end{array}$ & $\begin{array}{l}5 \text { (Tabiin } \\
\text { junior) }\end{array}$ \\
\hline 3 & $\begin{array}{l}\text { Abdul } \\
\text { Warits }\end{array}$ & $102 \mathrm{H}$ & $180 \mathrm{H}$ & Basroh & $\begin{array}{l}\text { Abu } \\
\text { Ubaidah }\end{array}$ & $\begin{array}{l}\text { Tsiqoh } \\
\text { Tsubut }\end{array}$ & $\begin{array}{l}8 \text { ( atbaut } \\
\text { tabi' in } \\
\text { pertengahan) }\end{array}$ \\
\hline 4 & $\begin{array}{l}\text { Imron } \\
\text { Ibnu } \\
\text { Maisarah }\end{array}$ & $\begin{array}{l}\text { Tidak } \\
\text { Diketahui }\end{array}$ & $222 \mathrm{H}$ & Basroh & $\begin{array}{l}\text { Abu Al- } \\
\text { Hasan }\end{array}$ & Tsiqoh & $\begin{array}{l}10 \text { (Senior } \\
\text { tabi'ut atba, } \\
\text { tidak bertemu } \\
\text { dengan } \\
\text { tabi'in) }\end{array}$ \\
\hline
\end{tabular}

Tabel di atas adalah daftar rawi sanad hadis yang sedang diteliti. Tabel ini menggambarkan periwayatan hadis dari pertama hingga akhir. Tabel di atas bertujuan untuk untuk mengetahui eksintensi apakah benar hadis tersebut terdapat dalam buku-buku hadis, mengetahui sumber otentik suatu hadis dari buku hadis apa saja didapatkan, mengetahui ada berap tempat hadis dengan sanad yang berbeda di dalam buku hadis atau buku induk hadis, dan untuk mengetahui kualitas hadis (Muhammad, 2016). Derajat kualitas suatau hadis dianggap shahih jika ia telah memenuhi beberapa kriteria. Ulama muthakhirin telah memberikan penjelasan secara tegas mengenai hadis shahih, seperti yang dikemukakan ibnu al-Shalah, yaitu: a) Sanadanya bersambung kepada Nabi, b) Seluruh periwayatan adil dan dhabit, dan c) Terhindar dari Syaz dan Ilat. Penegasan tersebut meliputi sanad dan matan hadis (Nasir, 2008).

Tidak semua hadis mempunyai jumlah sanad yang sama, ada hadis yang jumlah sanadnya empat seperti contoh di atas bahkan ada juga yang jumlahnya lebih dari itu. Dalam hubungannya dengan sanad, maka kita juga harus mengenal istilah musnid, musnad, dan isnad. Adapun yang disebut dengan musnad adalah hadis yang diriwayatkan dan disebut di dalamnya seluruh jumlah sanadnya hingga sampai Rasulullah. Musnid sendiri adalah orang meriwayatkan sebuah hadis dengan menyebutkan sanadnya. Sedangkan isnad adalah menerangkan atau menjelaskan sanadnya hadis(Ulin, 2013).

\section{Larangan Zina (Larangan Berhubungan Badan di Luar Pernikahan)}


Secara terminologi zina berarti melakukan hubungan sexsual antar laki-laki dan perempuan diluar ikatan pernikahan. Menurut Sayyid Qutub, bahwasanya perbuatan zina berisi berbagai pembunuhan. Alasaan kenapa disebut membunuh adalah karena mengalirkan matereri kehidupan tidak pada tempat seharusnya, dan biasanya diikuti dengan keinginan untuk tidak menanggung konsekuensinya dengan membunuh janin, baik sebelum dilahirkan atau sesudah kelahirannya. Jika janin masih hidup, maka biasanya dia menghadapi kehidupan yang buruk, atau hidup yang kejam. Zina juga membunuh dalam aspek lain, membunuh masyarakat tempat zina tersebut, yang mengakibatkan hilangnya nasab, hubungan darah tercampur aduk, dan kesatuan masyarakatpun menjadi retak. Zina juga membunuh masyarakat dari sisi lain, karena kemudahan melampiaskan syahwat dapat mengakibatkan kebutuhan rumah tangga menjadi utama. Zina juga mengakibatkan keluarga sebagai beban dan menjadi kehilangan alasan atas pembentukannya. Padahal keluarga merupakan tempat pembibitan yang seharusnya bagi generasi yang sedang berkembang, dimana fitrahnya keluarga sebagai lingkungan yang menjadi penentu baik dan buruknya seorang anak. Al-qur'an memperingatkan agar tidak mendekati zina, dan ini merupakan tindakan ekstra pencegah, karena zina terjadi karena dorongan syahwat yang menggebu, sehingga tindakan ekstra pencegah untuk tidak mendekati itu lebih menjamin karena mendekati sebab-sebab zina itu sangat beresiko terjadinya prilaku tersebut. Maka dari itu, Islam memutuskan sebab-sebab yang mendorongnya agar tidak terjerumus di dalamnya. Islam melarang pembauran antara laki-laki dan perempuan, memerintahkan puasa untuk menahan syahwat, menjatuhkan hukuman yang sangat berat bagi pelaku zina, itu semua bertujuan untuk menjaga masyarakat Islam dari kerusakan (Ika, 2018). Ahmad Mustafa Al-Maraghi dalam tafsiranya pada surat Al-Isra' bahwasanya perzinahan itu membawa kepada banyak masalah, hanya karena sebuah kehormatan pelaku zina memungkinkan untuk membunuh janin hasil hubungan terlarangnya itu (Nur, 2020).

Meninjau bahaya yang ditimbulkan oleh pelaku zina merupakan bahaya yang termasuk besar, dan perilaku tersebut juga bertentangan dengan dengan norma yang diberlakukan untuk menjaga kejelasan sanad, menjaga kesucian dan kehormatan diri, serta mewaspadai permusuhan dan perasaan benci yang diakibatkan perusakan terhadap istri, saudara perempan perempuan dan ibu mereka. Melihat banyaknya dampak negative yang ditimbulkan, praktik zina jelas dapat merusak tatanan kehidupan dan dapat dikelasifikasikan bahwa bahaya perzinahan setingkat di bawah bahaya pembunuhan(Al-jauziyah, 2016). Islam tidak hanya melarang perbuatana zina, tetapi juga Islam melarang untuk mendekati zina. Dosa zina di dalam Islam disertkan dengan dosa membunuh dan dosa dari perbuatan syirik. Rasaullah SAW mengatakan 
bahwa zina merupakan dosa terbesar kedua setelah syirik. Salah satu perbutan mendekati zina yang kerap kita jumpai yaitu khalwat. Keadaan dimana laki-laki dan perempuan berduaan tanpa adanya ikatan pernikahan, prilaku tersebut sering kali terjadi pada remaja-remaja dan anak muda (Bagas, 2019).

Pada era modern ini bisa dikatakan keadaan sekarang sangatlah miris. Perlahan keadaan sekelompok orang mulai dibutakan oleh gemerlapnya kehidupan. Manusia lebih mencondongkan dirinya untuk mngikuti keingingnan nafsu, terkhusus zina. Sebagian manusia seakan hilang kesadaran akan syariat dan pura-pura lupa akan norma syariat yang berlaku khususnya bagi masyarakat beragama Islam. Padahal dengan jelas Al-qur'an menyatakan akan perilaku semacam adalah perbuatan yang diharamkan. Pada akhirnya sekarang menjadi permasalahan bagi seluruh umat Islam. Kebanyakan dari mereka dipengaruhi oleh budaya kebarat-baratan yang bertentangan dengan ajaran agama, dan sekarang banyak sekali orang yang terpengaruhi oleh budaya tersebut (Tamrin, 2019).

\section{Kesimpulan}

Zina merupakan tindakan yang menyalahi aturan baik secara agama maupun hukum di Indonesia. Secara pengertian agama dan hukum di Indonesia zina memang memiliki makna yang berbeda, tetapi tetap saja kedua pengertian tersebut memiliki subtansi yang sama perihal zina. Ketika praktik zina dilakukan secara sembunyi-sembunyi dan hanya diketahui oleh pelaku saja, perilaku tersebut masih dalam ranah dosa pribadi. Sedangkan berbeda halnya apabila masyarakat telah mengetahui akan hal itu, hal tersebut akan menjadi perusak tatanan kehidupan di masyarakat sehingga menjadi dosa sosial. Maka dari itu taubat saja tidak cukup, melainkan dengan memberi hukuman terhadap pelakunya. Meninjau dampak negatif yang ditimbulkan oleh pelaku praktik zina merupakan bahaya yang tergolong besar, perilaku tersebut juga sangat bertentangan dengan aturan agama yang diberlakukan untuk menjaga kejelasan sanad pada keturunan, menjaga kesucian dan kehormatan, serta sebagai pencegah permusuhan dan perasaan benci yang diakibatkan oleh korban praktik zina. Melihat banyaknya bahaya yang ditimbulkan, praktik zina jelas dapat merusak kehidupan di masyarakat dan prilaku tersebut dapat dikategorikan bahwa bahaya zina hampir setara dengan bahaya pembunuhan. Diharapkan hasil penelitian ini memberikan manfaat bagi semua kalangan dan dapat menambah pengetahuan tentang Islam terutama yang berkaitan dengan hadis larangan zina. Diakui penelitian ini memiliki keterbatasan dalam menyusun kerangka berpikir dalam pembahasan hadis larangan zina sehingga dibutuhkan penelitian yang komprehensif, integral dan mendalam. Penelitian ini 
Jurnal Riset Agama, Volume 1, Nomor 2 (Agustus 2021): 365-374

Salis Abdalah Hatami/Hadis tentang Berhubungan Badan di Luar Pernikahan

merekomendasikan pentingnya penyuluhan kepada semua khalayak muslim akan larangan dan bahaya yang ditimbulkan zina.

\section{Daftar Pustaka}

Akib, N. (2009). Kesahihan Sanad Dan Matan Hadits: Kajian Ilmu-Ilmu Sosial. Shautut Tarbiyah, 15(1), 102-119.

Al-Jauziyah, I. I. Q. (2016). Jangan Dekati Zina. Bekasi: Darul Haq.

Amalia, M. (2018). Prostitusi dan Perzinahan dalam Perspektif Hukum Islam. Tahkim (Jurnal Peradaban Dan Hukum Islam), 1(1), 68-87. https:/ / doi.org/10.29313/tahkim.v1i1.3265

Bagas, M. (2019). No TitlePESAN DAKWAH LARANGAN MENDEKATI ZINA.

Bahiej, A. (2003). Tinjaun Yuridis atas Delik Perzinahan ( Overspel ) dalam Hukum Pidana Indonesia. Sosio-Relegia, 2(2), 1-22.

Darmalaksana, W. (2020). Formula Penelitian Pengalaman Kelas Menulis. Jurnal Kelas Menulis UIN Sunan Gunung Djati Bandung. http://digilib.uinsgd.ac.id/32620/

Fatih, M. (2019). Pendidikan Seks dalam Al-Qur'an; Perspektif Tafsir Tarbawi tentang Larangan Mendekati Zina. Ta'dibia: Jurnal Ilmiah Pendidikan Agama Islam, 8(2), 7-14. https:/ / doi.org/10.32616/tdb.v8.2.176.7-14

Gunawan, I. (2013). Kualitatif Imam Gunawan. Pendidikan, 143.

Huda, S. (2015). Zina dalam Perspektif Hukum Islam dan Kitab Undang Undang Hukum Pidana. HUNAFA: Jurnal Studia Islamika, 12(2), 377. https:/ / doi.org/10.24239/jsi.v12i2.401.377-397

Kisworo, B. (2016). Zina dalam Kajian Teologis dan Sosiologis. AlIstinbath: Jurnal Hukum Islam, 1(1), 1-24.

Hadi Wihyono, Achmad Manaf, L. A. (2020). Pacaran dan Zina Kajian Kekinian Perspektif al-Qur'an. SAMAWAT, 4(2), 48-55.

Hadziq, S. (2019). Pengaturan Tindak Pidana Zina Dalam KUHP Dikaji Dari Perspektif Living Law. Lex Renaissance, 4(1), 25-45.

Hilman, D. (2014). Delik Perzinahan Ditinjau dari Perspektif Hukum Islam. YUSTISI, 1(1).

Setiadini, I. (2018). "Hakikat Larangan Berzina Dalam Alquran (Kajian Atas Perspektif Sayyid Qutub Dalam Tafsir Fi Zilälil Quran)(Doctoral dissertation, Universitas Islam Negeri" SMH" Banten).

Ishaq. (2018). Perbandingan Sanksi Zina dalam Hukum Pidana Adat Desa Koto Lolo dan Kitab Undang-undang Hukum Pidana. Ar-Risalah, 18(47-61).

Kisworo, B. (2016). Zina dalam Kajian Teologis dan Sosiologis. AlIstinbath: Jurnal Hukum Islam, 1(1), 1-24.

Muhammad, Q. (2016). Metode Takhrij Hadis dalam Menakar Hadis Nabi. El Ghiroh, 11(2), 24-34. 
Jurnal Riset Agama, Volume 1, Nomor 2 (Agustus 2021): 365-374

Salis Abdalah Hatami/Hadis tentang Berhubungan Badan di Luar Pernikahan

Nur, S. (2020). Larangan Mendekati Zina (Studi Tafsir Alquran Surat AlIsra'Ayat 332 Menurut Para Muafassir).

Tamrin. (2019). Zina dalam Perspektif Al-Qur'an. MUSAWA, 11(1), 1-13.

Ulin, N. (2013). Kritik Sanad: Sebuah Analisis Keshahihan Hadis. An Nur, $5(1), 26-47$. 